\title{
Imagining urban interactions: strategies for exploring future design landscapes
}

\author{
Michael Smyth \\ Centre for Interaction Design \\ Edinburgh Napier University \\ 10 Colinton Road \\ Edinburgh, UK \\ m.smyth@napier.ac.uk
}

\author{
Ingi Helgason \\ Centre for Interaction Design \\ Edinburgh Napier University \\ 10 Colinton Road \\ Edinburgh, UK \\ i.helgason@napier.ac.uk
}

\begin{abstract}
For designers, attempting to respond to unknown design spaces can be a daunting task. This paper describes a series of workshops that presented rapid ethnographic design methods in city streets as a way of exploring human behaviours, and recording their traces. One instance of the workshop is described in detail to highlight the connections between the data gathering and the concept generation phases. Emphasis was placed on discovering "bleed points" where the virtual world can connect with the physical world. This activity was carried out with the aim of considering possibilities for interaction scenarios in future urban settings. The ethnographic observation and data gathering process itself was paramount in these workshops, enabling designers to engage with existing and potential interaction situations. Early concept development was the endpoint of this process, and designed responses were developed primarily to describe the emergent urban design space, rather than as a step towards any finished system or product.
\end{abstract}

Ethnographic methods, case study, requirements generation, urban computing, early design concepts

\section{INTRODUCTION}

Requirements generation has a strong tradition within the field of Human Computer Interaction $(\mathrm{HCl})$. Numerous methods have been adopted from a variety of disciplines and these have been tailored to address the specific demands of $\mathrm{HCl}$. Whether from a quantitative or qualitative perspective, requirements methods seek to articulate the needs, desires and expectations of users. $\mathrm{HCl}$, by its nature, brings a technical focus to the articulation of requirements and through this process practitioners contribute to the improvement of existing systems. But what happens when we need to extend that horizon in order to identify emergent themes? How do you begin to design concepts when you don't know what the design space will look like, let alone who the user population will be?

Increasingly our experiences are urban and are enhanced by technology that enables simultaneous existence in both the virtual and real worlds. Such technology offers a number of bridges between these worlds but in so doing places an increased tension on the sense of place and subsequently the identity of the individual. Identity has many components that have to be woven in our everyday lives. It is postulated that in order to cope with the demands of our society, people must be capable of switching between identities actively and quickly while stitching these different identities in place (Hall, 1991).

Furthermore, it is possible that a 'fragmentation' of identity is part of our experience of modernity (Benjamin, 1997). Today identity is just as much about stitching multiple identities in separate virtual places as it is with their physical counterparts. Our sense of place, both physical and virtual, contributes to our feeling of presence and the subsequent identity that is created, maintained and communicated. It is at the border of these physical and virtual worlds that the urban dweller's sense of place resides and it is through collaborative enquiry, using techniques such as those described in the paper, that the crossing points can be identified and shaped.

This paper reports on a workshop that explored the relationship between the physical and virtual layers that increasingly characterise the urban environment. In particular, the focus was on the 'bleed points' where virtual and physical layers coalesce and where the resulting behaviours and activities could provide insights into future interactions. 


\section{DESIGN CONTEXT: SHAPING THE FUTURE}

When considering the next generation of products and services it is notoriously difficult to disassociate from current technology and to move beyond iterative improvements. The temptation is to stay in the comfort zone of incremental development of existing designed artefacts and systems, rather than venturing out into the world of radically transformative design. The situation has been further exacerbated by the increased use of distributed, embedded, and interconnected technologies in society, both personal and situated in the environment. This is not to criticise the user centred approach so beloved of $\mathrm{HCl}$, but it is to recognise its limitations.

Traditional $\mathrm{HCl}$ tends to take a rational, engineering focussed approach, that of problem-solving, where insufficiently structured problem statements cause difficulties in arriving at appropriate solutions. Part of the resolution of this situation rests on application of methodologies that attempt to refine and clarify the problem statement itself in order to move towards appropriate systems. Interaction Design, as a more recently developed discipline, takes a more 'designerly' approach to this activity by considering both the problem and the solution in a more fluid and intertwined manner, accepting lack of situational certainty and embracing the contextual and evolutionary nature of designed systems in use (Dorst, 2006).

One purpose of design can be to shape strategy and set agendas for future generations of technology and design outcomes. The challenge facing such early stage concept generation is to project forward by tapping into higher level needs and desires that are often not obviously apparent. Critical Design (Dunne, 1999) presents design as a catalyst or provocation for thought. It is a strategy for exploring the space that lies tantalisingly beyond the current and the now. By contextualising this approach at the edges of our knowledge, it is possible to use design to create 'design fictions' (Bleecker \& Nova, 2009). Such fictions have the effect of humanising the future and thereby enabling us to focus on the minutiae of behaviour and the subsequent questions that are revealed through the exposure of our needs, desires, habits, rituals, values and priorities. At the core of Critical Design is the attempt to challenge our assumptions and preconceptions about the role that products and services play in everyday life.

\section{URBAN INTERACTION DESIGN (UIXD)}

The urban space presents one of the greatest challenges to researchers and designers. Its fluctuating demographics and ever more layers of digital information have resulted in cities that are an aggregation of public and private spaces. Only by the interaction with and through such spaces will the complexity of urban 'sense making' be revealed and a shared identity emerge.

Increased urbanisation will be a defining trend for the world's population in the first half of this century. As a consequence there will be an increase in population migration, both rural to urban and between urban areas. What is less certain is how cities and their inhabitants will respond to these changes. An approach for informing the design of future technology in an urban context is to foreground urban life's experiential qualities. Central to this goal is the desire to reflect urban experiences in technology design that will, in turn, transform these experiences so that new behaviours can emerge.

It is estimated that currently just one hundred cities account for $30 \%$ of the world's economy and almost all of its innovation (Khanna, 2010). The net effect of this economic shift has been the emergence of the City State: a self sustaining economic entity inhabited by experienced and sophisticated urbanites, who are ever more demanding but also increasingly open minded to experiencing new urban products, services and campaigns that, in turn have to reflect the complexity and multifaceted nature of city living. These products will be increasingly linked to a city's culture, its brand and its identity as they seek to capture a city's character for its inhabitants. Technology continues to underpin this phenomenon, both at the level of the city or, increasingly, the neighbourhood. The urban space has become a hybrid space comprising of layers of digital information aimed at the different demographics that inhabit the city. The emergent behaviours and the nature of the interaction will be a growing challenge for researchers, designers and technologists.

\section{THE HYBRID CITY}

It is envisaged that the urban spaces of the future will be saturated with both visible and hidden media that gather and transmit information. How we as physical beings connect with, interpret and shape the increase of data residing in our environment will be a significant challenge. The forms in which this information will be presented, and how we decide to conceptualise it, are as yet unknown. Will the technologically enriched environment adapt to accommodate human/city contact points, and, in response, how will we choose to interact with and navigate through this information landscape? Today's urban experience is enhanced by 
technology that increasingly enables simultaneous existence in both the virtual and real worlds.

There is an increasing trend towards the use of aggregate data when projects seek to reveal or make explicit invisible urban phenomena such as pollution, noise, patterns of movement and peoples' emotional reaction to places. The city has become a kind of 'blogject' that provides data for applications and services that seek to visualize urban dynamics in real time thereby helping individuals to make informed decisions about how they behave in the physical environment. Examples of such prototype systems include Christian Nold's Biomapping (Nold, 2010), mapping emotional arousal with geographic location; Tripwire (Hirsh, 2010) by Tad Hirsh monitored noise pollution while Sensing Atmosphere (Paulos, Honicky \& Goodman 2007) measured air pollution. Each of these prototypes provide different ways for viewing, interpreting and interacting with the urban environment.

\section{THE RAPID ETHNOGRAPHY WORKSHOPS}

Humans have always been in constant engagement with their surroundings, often without being consciously aware of the process or nature of this interaction. By investigating the activities that currently take place in this liminal space we may be able to identify important themes and issues. Taking inspiration from ethnographic design research methods, a series of workshops were organised that took an experimental approach to the recording of these human activities. A particular aim was to discover the intersections and crossing points between the human and the digital worlds. By using the everyday technologies that people carry and have to hand, the participants in the workshops were provided with a new perspective on the traditional techniques that designers have employed, such as the creation of scrapbooks, moodboards and sketches. The use of camera phones as quick recording and note-taking devices is becoming an increasingly common and familiar activity, and so it was envisaged that this approach would widen opportunities for participation in early phases of the design process. These approaches can assist the technologists and designers of the future as they work to shape physical and virtual environments in such a way that they can be made sense of and manipulated.

\subsection{Research Questions}

The workshops addressed questions such as:

- What form will the information landscape take?

- How will people adapt their behaviours, and indeed how will the nature of the urban landscape alter as increased amounts of information is overlaid on the physical environment?

- What new products and services will be available given the increase of targeted information aimed at specific communities and interest groups?

- Will this result in an increase in segmentation and fragmentation associated with the urban experience leading to the possibility of the creation of multiple experiences of the same physical space?

- What will inform the visual aesthetic of the future information landscape?

The workshops explored the 'bleed points' where the physical and virtual worlds connect or indeed, disconnect. As a starting point, examples were drawn from current advertising, product design and digital art works. Furthermore the workshops focused on the small ideas that underpin the 'big questions' that too often overwhelm researchers. It has been said that the 'devil is in the detail', and so the workshops invited participants to adopt an attitude of curiosity as they sought to unpack the nature of peoples' rituals, habits and priorities, focusing, in particular, on the potential for behaviour associated with existing technologies.

\subsection{Activities}

Each of the workshops was comprised of the following activities: an introductory presentation that orientated the participants to the aims of the workshop and the context of the data gathering activity. Immediately after this, the detail of the workshop activity was introduced. Based on their experience and interests, participants undertook a collaborative data gathering activity. Each workshop employed (very) rapid ethnography as a means of gathering rich visual data about the urban space in which we engage. This involved the participants using camera phones to record images of the urban environment. In particular, participants were asked to go out into the immediate surroundings of the workshop to photograph examples of 'close' interactions between humans and their environment. These images formed the basis of a 'digital scrapbook' that was transformed into a visual presentation and used as a stimulus for participants' discussion and debate of the emergent themes.

\section{WORKSHOP REPORT FROM DESIGNING INTERACTIVE SYSTEMS CONFERENCE, AARHUS (DIS 2010)}

The remainder of the paper will focus on the instance of the one-day workshop run at DIS 2010 under the title of 'Informing the Design of the Future 
Urban Landscape'. By its nature, work on urbancentred technological design is a complex and multidisciplinary undertaking, even more so when considering issues that are likely to come to the fore in the next few years and beyond. The attendees at the Designing Interactive Systems 2010 (DIS) conference workshop were primarily researchers from $\mathrm{HCl}$ and related fields, and most also had experience of creative design practice. The common thread between them was a desire to investigate and articulate the issues that designers and technologists will have to address in the near future in their creative practice.

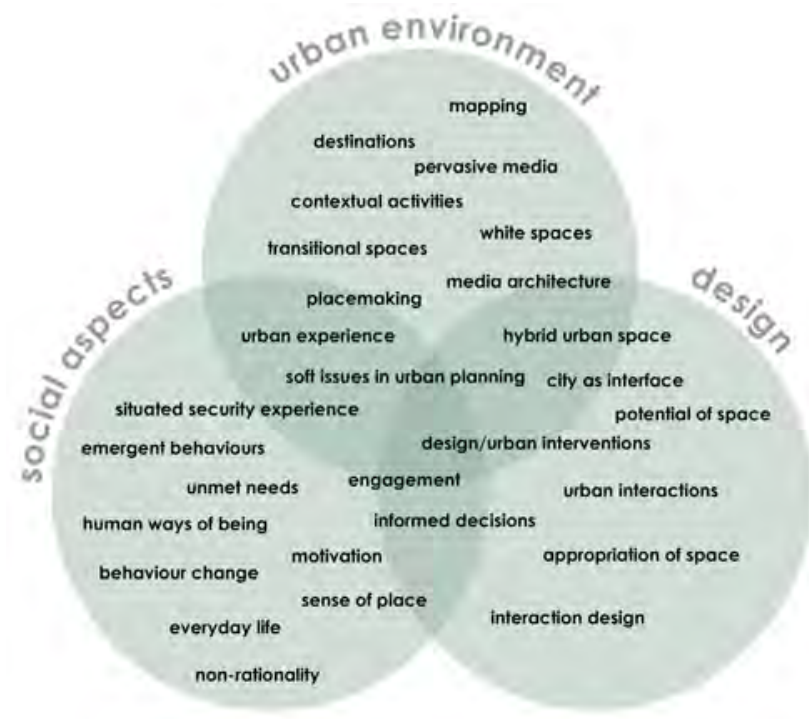

Figure 1: Diagram of participants' collected keywords, grouped after the workshop into broad themes.

As an initial exercise, participants collated a list of their research interests and keywords in order to understand a little more about the group's viewpoints and priorities (Figure 1). Participants then used the design research methods discussed in this paper to document the 'bleed points' where the physical and virtual worlds connect, or could potentially connect, out in the surrounding urban area.

They were given an hour to go out into nearby streets, in pairs, to take photos on their own camera phones. The emphasis was on observing situations and gathering examples in the form of images, without pause for reflection at this stage. These images were compiled into a collective digital scrapbook to stimulate the subsequent reflection and debate of emergent themes (Figure 2). This was done by sending the images to an online photo sharing website, using an email address given to the participants. By the time they returned to the workshop room from their fieldtrip, most of the images were already incorporated into a large-screen display.

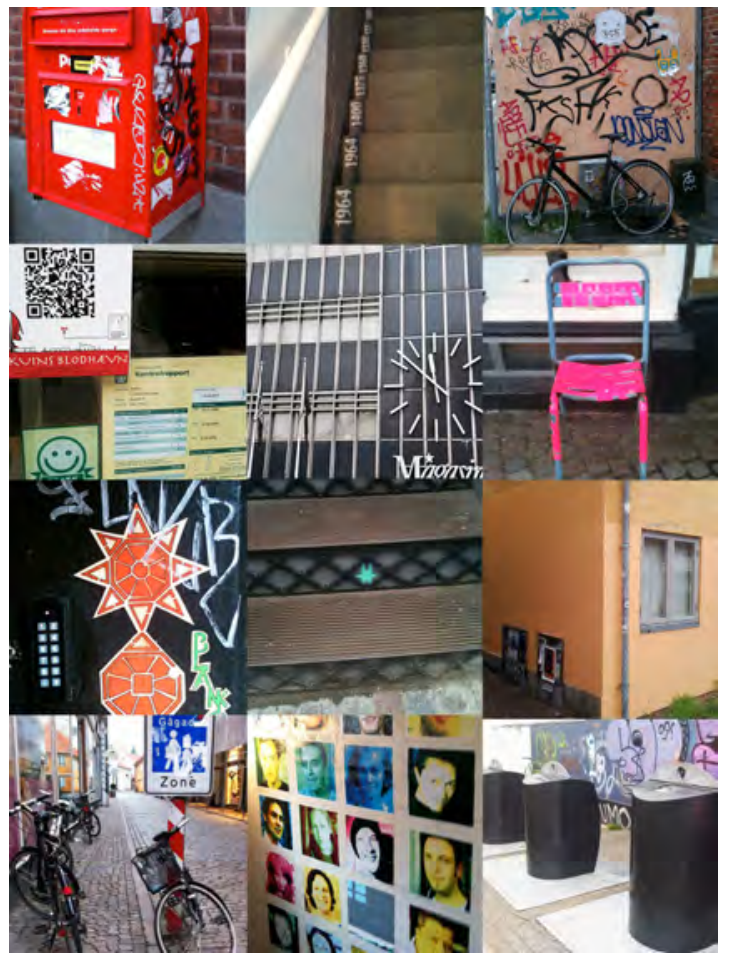

Figure 2: Some of the images collected by participants at the DIS 2010 workshop.

Participants commented that they found many more examples of "bleed points" than they expected to, and that the activity encouraged close observation, as well as inspiring conceptual connections between tangible objects and imagined behaviours. The next stages involved reflection, discussion and brainstorming as a whole group. The images gathered by the participants were displayed as a slideshow throughout this phase, acting as reminders and triggers to describe observations to each other.

The group as a whole arrived at a list of suggestions and ideas to pursue, based on their discussions. Then, in three smaller groups, participants selected the most promising design concepts (one per group) to develop to the next stage. The three final concepts explored the following themes:

- The city as shelter from interaction :: mobile, re-configurable shelters that provide inhabitants with momentary respite from the demands of interaction.

- Shared spaces :: multiple viewpoints of the urban environment, depending on context and role, the tourists' and inhabitants' gaze.

- Kinetic Crossing :: harvesting energy from pedestrian movement as a source of power and as a driver for 'just in time' signage. 


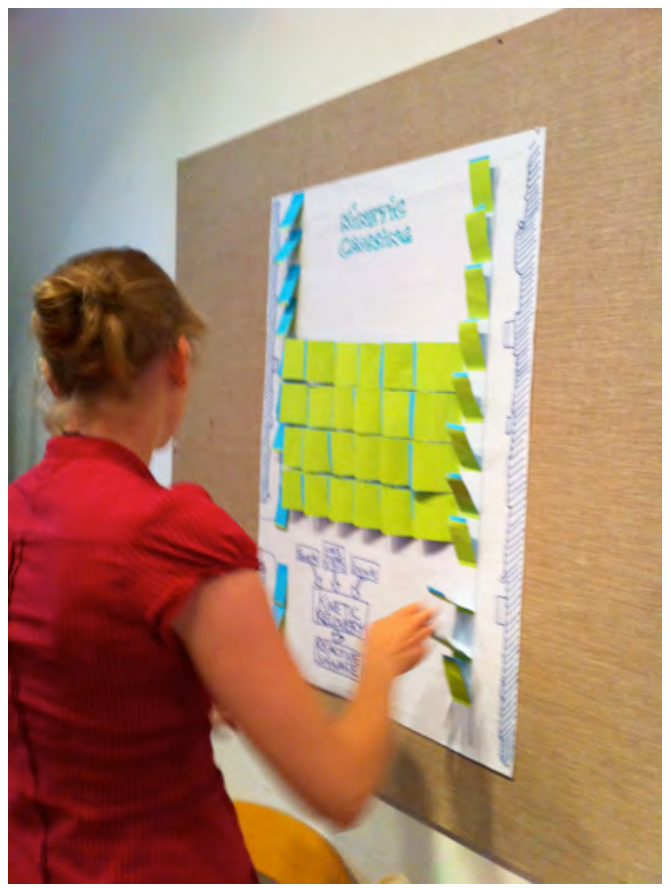

Figure 3: Presentation of Kinetic Crossing design concept to the group.

Finally, each group presented their idea to the whole group, using flipchart paper, pens and sticky notes to describe their work. (Figure 3) The day concluded with discussion around wider themes that had emerged from the day's activities, and potential collaborations and activities for the future.

\section{CONCLUSIONS}

The case study presented here used lightweight, ethnographically informed methods in order to inspire the creation of design responses to potential future situations. While the workshop process involved both observation and data collection, a key factor was that the designers themselves were carrying out both of these tasks. The view of the organisers is that these processes of observation and recording are critical to designers as they engage with the design space. The workshop was structured to encourage collaborative observation, practical design activities, reflection and wider discussions. The data collection and design generation phases of the workshop in particular encouraged the making of connections between detailed observational insights, and higher level ideas and debates. Discussion focussed around social and behavioural interactions within the urban landscape using media technologies. It was recognised that exploratory, open-ended methods of eliciting and reflecting upon human behaviours, needs and desires would be valuable in determining the shape of the future design space. The recorded photographs that participants gathered and shared were useful as memory aids and as focus for discussion. However, it is in the act of looking, considering and framing the photographs that the context and its possibilities begin to be fully grasped by the designer. This insight can then be shared and developed through incorporation into the brainstorming phase of a collaborative design process.

\section{ACKNOWLEDGEMENTS}

The authors would like to thank the participants in the Aarhus workshop, and the organisers of the DIS 2010 conference.

\section{REFERENCES}

Benjamin, W. (1997) Charles Baudelaire: A Lyric Poet in the Era of High Capitalism, Verso Classics, London.

Bleecker, J. Nova, N. (2009) A synchronicity: Design Fictions for Asynchronous Urban Computing, The Architectural League of New York http://www.situatedtechnologies.net

Dorst, K. (2006) Design problems and design paradoxes, Design Issues, vol. 22 (3) pp. 4-17

Dunne, A. (1999) Hertzian Tales - Electronic Products, Aesthetic Experience and Critical Design, RCA/CRD Research Publications, Royal College of Art, London

Hall, S. (1991) Stitching yourself in Place, Annual Magazine of the European Network for Cultural and Media Studies, Vol 1, Amsterdam, 4-13.

Hirsch, T. http://web.media.mit.edu/ tad/htm/trip wire.html, Accessed 7 June 2010.

Khanna, P. (2010) Beyond City Limits, www.foreignpolicy.com

Nold, C. (2010) Emotional Cartography Technologies for the Self, Creative Commons.

Paulos, E., Honicky, R. J. and Goodman, E. (2007) Sensing Atmosphere, Proc of Embedded Network Sensor Systems (SenSys07), 6-9 Nov, Sydney, Australia. 